\title{
Predictive models for the growth of Cronobacter sakazakii in reconstituted powdered infant formula
}

\author{
Audrey Wesseling, Padmanabha Reddy Velugoti, Jeyamkondan Subbiah and Harshavardhan Thippareddi
}

Received: 03 August 2018 / Accepted: 18 December 2018 / Published online: 21 February 2019

(c) Indian Dairy Association (India) 2019

\begin{abstract}
Cronobacter sakazakii has been implicated in foodborne illnesses in neonates and infants resulting from the consumption of contaminated infant formula. The objective of this research was to develop predictive models for the growth of C. sakazakii in infant milk formula (IMF) and infant soy formula (ISF). Growth kinetics for a five strain cocktail of $C$. sakazakii were obtained at several isothermal conditions at $8.5,10,15,20$, $25,28,32,35,37,40,42,45$, and $47^{\circ} \mathrm{C}$ in reconstituted IMF and ISF. Initial protocol resulted in clumping of colonies leading to difficultly in enumerating C. sakazakii. Protocol was then modified by addition of Tween- 80 and stomaching the samples, which resulted in breaking up of colonies effectively. The growth data were fitted to three primary models (Baranyi, Gompertz, and Logistic) to describe the growth of $C$. sakazakii at each isothermal condition. For IMF, the psuedo- $\mathrm{R}^{2}$ and the root mean square error (RMSE) ranged from 0.96-0.99 and 0.07-0.34 log CFU/ $\mathrm{mL}$, respectively. For ISF, the psuedo- $\mathrm{R}^{2}$ and the RMSE ranged from $0.98-0.99$ and $0.08-0.27 \log \mathrm{CFU} / \mathrm{mL}$, respectively. Two different secondary models were used to describe the effect of temperature on growth rate of C. sakazakii for each product. For the modified Ratkowsky's equation, psuedo- $\mathrm{R}^{2}$ and the RMSE values were 0.99 and $0.004-0.0169(\log \mathrm{CFU} / \mathrm{mL}) / \mathrm{h}$, respectively.
\end{abstract}

\footnotetext{
Audrey Wesseling

Food Science \& Technology, 236 FIC, East Campus, University of Nebraska, Lincoln, NE 68583, USA

Padmanabha Reddy Velugoti

Faculty of Dairy Science, Sri Venkateswara Veterinary Science, Tirupati 517502, Andhra Pradesh, India

Jeyamkondan Subbiah $(\square)$

Biological Systems Engineering, 212 L.W. Chase Hall, East Campus, University of Nebraska, Lincoln, NE 68583, USA

E-mail:deandairy.svvu@gmail.com

Harshavardhan Thippareddi

Biological Systems Engineering, 212 L.W. Chase Hall, East Campus, University of Nebraska, Lincoln, NE 68583, USA
}

For the Gamma model, psuedo- $\mathrm{R}^{2}$ and the RMSE values were 0.99 and $0.004-0.006(\log \mathrm{CFU} / \mathrm{mL}) / \mathrm{h}$, respectively. C. sakazakii grew faster in IMF, when compared to ISF. Primary and secondary models were integrated and solved numerically to determine the growth of C. sakazakii at varying temperature profiles. Six dynamic models were validated with one sinusoidal and three 'real-life' temperature profiles. The dynamic models from Baranyi (RMSE ranging from 0.12-0.39 $\log \mathrm{CFU} / \mathrm{mL}$ ) and logistic models (RMSE ranging from 0.25-0.79 $\log \mathrm{CFU} / \mathrm{mL}$ ) predicted C. sakazakii growth better, compared to the Gompertz dynamic models (RMSE ranging from 0.46-0.67 $\log \mathrm{CFU} / \mathrm{mL}$ ). These predictive models can help improve microbial risk assessment and develop appropriate risk management strategies.

Keywords: Cronobacter sakazakii, Infant formula, Predictive modelingmodelling

\section{Introduction}

Colonization of neonates with gram-negative bacteria is inevitable (Arseni et al., 1987) with the most common being Klebsiella, Serratia, and Enterobacter. It is estimated that the prevalence of neonatal sepsis and meningitis is roughly 1-5/1,000 live births, but increases to $1 / 230$ in premature infants (Ferrieri 1990). Increased susceptibility stems from maternal and environmental factors. Cross contamination of newborn infants from personnel or from contaminated equipment is increased when combined with immunologic immaturity of preterm infants (Ferrieri 1990).

Enterobacter sakazakii is a newly recognized yellow-pigmented species of the family Enterobacteriaceae (Farmer et al., 1980). With new polyphasic taxonomic approaches, C. sakazakii was reclassified into a new genus, Cronobacter (Iversen et al., 2008). Cronobacter spp. is synonymous with $C$. sakazakii. Although the natural habitat and source of infection of $C$. sakazakii is questionable, foodborne illness outbreaks among infants in neonatal intensive care units (NICU) indicates strong correlation of $C$. sakazakii as a natural contaminant in powdered infant formula (PIF).

C. sakazakii has been isolated from a range of foods including UHT milk (Skladal et al., 1993) and reconstituted powdered infant 
formula (PIF) (Bar-Oz et al., 2001, Biering al., 1989, Muytjens et al., 1983, Noriega et al., 1990, Simmons et al., 1989, Van Acker et al., 2001). C. sakazakii can cause neonatal meningitis, bacteraemia, necrotizing enterocolitis, and necrotizing meningoencephalitis after ingestion (Iversen and Forsythe 2003). Though the number of reported outbreaks caused by $C$. sakazakii is low, the severity of the infection and a high mortality rate make it necessary to minimize and, if possible, eliminate the risk of contamination of such foods with the organism.

Minimizing the risk of illnesses resulting from $C$. sakazakii infection in infants requires (i) minimizing the risk of contamination of PIF at the processing facility and (ii) the potential risk of pathogen growth during preparation and feeding of the neonates/infants in the NICU. The hospital reported in Noriega et al. (1990) changed their protocol from rinsing their blender between preparing the formula, which had heavy growth of C. sakazakii, to terminal pasteurization of reconstituted formula in the bottles. The hospital in Himelright et al. (2002) changed their policy by completely replacing the principle formula type for NICU infants from powdered formula to a commercially sterile, ready-to-feed liquid formula. Although these changes are simple, processing and production of commercial, sterilized liquid formulas are generally more expensive and require larger transport and storage facilities (Van Acker et al., 2001).

Regardless of the measures implemented at processing facilities, it would be prudent to develop and implement guidelines at the hospitals and other similar settings to minimize the risk of pathogen growth during preparation and feeding of the infants. But even with specific guidelines, temperature abuse and improper handling of infant formula could occur. Accurate prediction of potential C. sakazakii growth in infant formula can help in improving microbial risk assessment and developing appropriate risk management strategies.

\section{Material and methods}

\section{Organism}

Five C. sakazakii isolates were obtained from environmental sources of a processing facility and stored at $-70^{\circ} \mathrm{C}$. Each strain was transferred three successive times in tryptic soy broth (TSB) (10 mL; Fisher) and incubated overnight at $35^{\circ} \mathrm{C}$. Each strain was then transferred to TSB and incubated at $35^{\circ} \mathrm{C}$ for $16-17 \mathrm{~h}$, separately to obtain cells in the exponential phase of growth. Five $\mathrm{mL}$ of TSB from each strain were then combined and centrifuged $2683 \times \mathrm{g}$ for $15 \mathrm{~min}$ at $4{ }^{\circ} \mathrm{C}$. The cell pellet was resuspended in $10 \mathrm{~mL}$ peptone water.

\section{Preparation, inoculation of infant formula, and enumeration}

Commercially available brands of milk and soy powdered infant formula were obtained from a grocery store. The formulations were prepared according to the manufacturer instructions in sterile containers using sterile, tap water. The infant formula was inoculated with the appropriate dilution of the mixed culture to provide an initial C. sakazakii population of $2.7 \pm 0.1 \log \mathrm{CFU} /$ $\mathrm{mL}$. Infant formula was manually mixed and $10 \mathrm{~mL}$ aliquots were transferred to sterile screw cap test tubes. The test tubes were then placed in water-baths set to temperatures of $8.5,10,15,20$, $25,28,32,35,37,40,42,45$, or $47^{\circ} \mathrm{C}$. Approximately 10 min was allowed for temperature stabilization. At least 12 samples were collected for each temperature (from the lag phase to the stationary phase) at various times to enumerate $C$. sakazakii. Samples from $8.5-20^{\circ} \mathrm{C}$ water-baths were submerged in a hot water-bath to quickly warm the sample to ambient temperature to aid in sampling as slime formation (ropiness) was observed at different sampling points. A $1 \mathrm{~mL}$ aliquot of Tween- 80 (1.0\% solution in distilled deionized water) was added directly to the sample and further dilutions were prepared using $0.1 \%$ Tween- 80 dilution blanks. Samples were then transferred to sterile stomacher bags (Nasco Whirl-Pak, $4 \mathrm{oz}$ ) and stomached for $2 \mathrm{~min}$ in a (Seward Model 400, Tekmar Company). Two independent replications for each temperature were performed using fresh culture and a new can of formula. Serial dilutions of the sample were prepared in sterile $0.1 \%$ Tween- 80 and plated on violet red bile glucose agar (VRBGA) in duplicate and incubated for $16-24 \mathrm{~h}$ at $35^{\circ} \mathrm{C}$. Typical red colonies were enumerated as $C$. sakazakii and counts were expressed as $\log \mathrm{CFU} / \mathrm{mL}$.

\section{Primary models}

Primary microbiological growth models describe the growth of microorganisms over time under constant environmental conditions such as temperature. Growth profiles were recorded for the 13 static temperatures. For each growth profile, parameters were calculated manually and specified into a preprogrammed non-linear regression program, PROC NLIN, in the SAS package (SAS, 2007) to fit the data using Marquardt iterative method for the estimation of the parameters.

\section{Baranyi's Model}

Baranyi and Roberts (1994) published the solution for the natural logarithm of the cell concentration, $y=\ln [x(t)]$, at constant temperature:

$$
\begin{aligned}
& y(t)=y_{0}+\mu_{b} F(t)-\log _{e}\left(1+\frac{e^{\mu_{b} F(t)}-1}{e^{\left(y_{\max }-y_{0}\right)}}\right),(1) \\
& \text { where, } F(t)=t+\frac{1}{v} \log _{e}\left(e^{-v t}+e^{-h_{0}}-e^{\left(-v t-h_{0}\right)}\right)
\end{aligned}
$$

Baranyi's model includes four parameters: $y_{0}$, initial microbial population (ln CFU/mL); $y_{\max }$, maximum growth (ln CFU/mL); $\mu_{b}$, Baranyi maximum specific growth rate $\left(\mathrm{h}^{-1}\right)$; and $h_{0}$ which is the product of $\left(\mathrm{h}^{-1}\right)$ and the lag phase duration $(\mathrm{h})$. is defined as the growth (ln CFU/mL) at time, (h). To determine the lag phase 
periods $(\mathrm{h})$, the converged values of was divided by the converged values

To evaluate the goodness of fit, pseudo- $\mathrm{R}^{2}$, a statistic closely corresponding to $\mathrm{R}^{2}$ in the non-linear case, was used (Schabenberger, 2005):

Pseudo $-R^{2}=1-\frac{\text { SS }(\text { Residua })}{\left.\text { SS }_{\text {(Total }} \text { Corrected }\right)}$,

where SS(Residual) is the sum of the squares of residuals and $\mathrm{SS}\left(\right.$ Total $\left._{\text {Corrected }}\right)$ is the total sum of squares.

The root mean squared error (RMSE) is calculated by

$$
R M S E=\sqrt{\frac{(O-P)^{2}}{N-p}}
$$

where $O$ and $P$ are observed and predicted microbial population in $\log \mathrm{CFU} / \mathrm{mL}$ and $N$ is the number of observations, and $p$ is the number of model parameters.

The model performance was evaluated using the Bias Factor (BF) and Accuracy Factor (AF) and were calculated using the following formulae:

$B F=\quad B F=10^{\sum \log (\mathrm{P} / 0) / \mathrm{N}}$

$A F=10^{\sum|\log (\mathrm{P} / \mathrm{O})| / \mathrm{N}}$

A BF value greater than 1 indicates the model over predicted and vice versa. An AF value of 1.1 indicates the average deviation of the predicted values from the observed values is $10 \%$ (Jeyamkondan et al., 2001).

\section{Modified Gompertz \& Logistic Models}

The modified Gompertz equation (Gibson et al., 1987, 1988)

$$
\mathrm{L}(t)=y_{o}+\left(y_{\max }-y_{o}\right) \times \exp \left[-\exp \left(-\mu_{g}(t-m)\right)\right]
$$

and the logistic equation (Gibson et al., 1987, 1988),

$$
\mathrm{L}(\mathrm{t})=\mathrm{y}_{\mathrm{o}}+\left(\frac{\mathrm{y}_{\max }-\mathrm{y}_{\mathrm{o}}}{1+\mathrm{e}^{\left(-\mu_{\mathrm{L}}(\mathrm{t}-\mathrm{m})\right)}}\right),
$$

containing the following parameters: $L(t)$ is the $\log (\mathrm{CFU} / \mathrm{mL})$ of cell concentration; and are the initial and final cell concentrations; $t$ the growth time; $=$ Gompertz maximum specific growth rate $\left(\mathrm{h}^{-}\right.$ $\left.{ }^{1}\right)$; = Logistic maximum specific growth rate $\left(\mathrm{h}^{-1}\right)$ and , the inflection point of the slope (h), and is a scaled version of with the relationship of $(\log \mathrm{CFU} / \mathrm{mL})$.

By manipulating the modified Gompertz model, Gibson et al., (1987, 1988) derived equations for the lag () and generation (GP) periods:

$$
\begin{aligned}
& \lambda=m-\frac{1}{G P_{\text {ho } \overline{\overline{d e l}}}} \frac{\log _{10}(2)}{r_{\max }} \\
& \text { and }
\end{aligned}
$$

\section{Secondary Models}

Secondary microbiological predictive models describe the maximum specific growth rate as a function of temperature.

\section{Modified Ratkowsky Model}

The modified Ratkowsky's equation (Zwietering et al., 1991),

$$
\mu_{\max }=a\left(T-T_{\min }\right)^{2}\left[1-\exp \left(b\left(T-T_{\max }\right)\right)\right.
$$

includes and parameters, which are theoretical minimum and maximum temperatures. The square root of, , and were plotted against temperature. A slope to the maximum value was determined and squared and used as the starting value for parameter $b$ in the modified Ratkowsky model. Parameters were entered into a preprogrammed non-linear regression program, PROC NLIN, in the SAS package (SAS, 2007) to fit the data using Marquardt iterative method for the estimation of the parameters. To predict the growth rate from the Gompertz and Logistic primary models, methods from Huang (2003) were used to model the growth rate.

\section{Gamma Model}

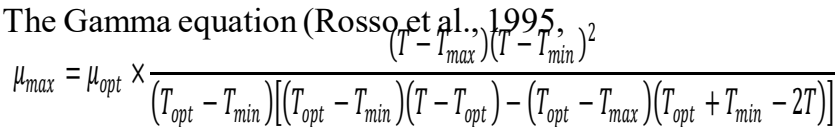

Jontains four parameters: $\mu_{\text {opt }}$, optimum maximum specific growth rate $\left(\mathrm{h}^{-1}\right) ; T_{\text {opt }}$, optimum temperature $\left({ }^{\circ} \mathrm{C}\right) ; T_{\min }$, theoretical minimum temperature $\left({ }^{\circ} \mathrm{C}\right)$; and $T_{\max }$, theoretical maximum temperature $\left({ }^{\circ} \mathrm{C}\right)$.

\section{Dynamic Model}

Dynamic models integrate the primary and secondary models to predict growth over time. Integrating the three primary models 
with the two secondary models resulted in six dynamic models. Huang (2003) differentiated Eq. (6) with respect to time and the regulting equation was

$$
\frac{d L}{d t}=\mu_{g}\left(y_{\max }-y_{0}\right) \times \exp \left\{-\exp \left[-\mu_{g}(t-M)\right]\right\} \times \exp \left[-\mu_{g}(t-M)\right]
$$

q. (5) can be rearranged as

$$
\begin{aligned}
& \frac{L-y_{o}}{y_{\max }-y_{o}}=\exp \left\{-\exp \left[-\mu_{g}(t-m)\right]\right\}(13) \\
& \ln \left(\frac{L-y_{o}}{y_{\max }-y_{o}}\right)=-\exp \left[-\mu_{g}(t-m)\right] .(14)
\end{aligned}
$$

By rearrangement of Eq. (6), and substitution of Eq. (13) and (13), Eq. (12) can be written as

$$
\frac{d L}{d t}=\mu_{g}\left(L-y_{o}\right) \ln \left(\frac{y_{\max }-y_{o}}{L-y_{o}}\right)
$$

Differentiating the Logistic equation (Eq. (7)) results in

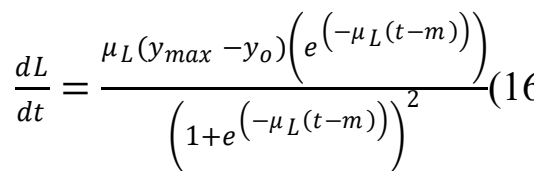

Eq. (7) can be rearranged as

$$
\begin{aligned}
& \left(y_{\max }-y_{o}\right)=\left(L-y_{o}\right)\left[1+e^{\left(-\mu_{L}(t-m)\right)}\right] \\
& {\left[1+e^{\left(-\mu_{L}(t-m)\right)}\right]=\frac{y_{\max }-y_{o}}{L-y_{o}}} \\
& e^{\left(-\mu_{L}(t-m)\right)}=\left(\frac{y_{\max }-y_{o}}{L-y_{o}}\right)-1
\end{aligned}
$$

By rearrangement of Eq. (7) and substitution of Eq. (17), (18), and (19), Eq. (16) can be written as

$$
\frac{d L}{d t}=\frac{\mu_{L}\left(L-y_{o}\right)\left(y_{\max }-L\right)}{\left(y_{\max }-y_{o}\right)}
$$

In Eq. (15) and (20), the initial value of $L$ must be given, but at L(0), L equals y_o, which makes the equation singular (Huang, 2003). To overcome this, Huang (2003) developed the pseudoinitial value of $\mathrm{L}$ by the equation $\mathrm{L}(0)=\mathrm{y} \_\mathrm{o}+\mathrm{L}(0)$.

In the case of the Baranyi model, the following two differential equations must be solved:

$$
\begin{aligned}
& \frac{d Q}{d t}=\mu_{b}(T(t)) \text { and }(21) \\
& \frac{d y}{d x}=\frac{1}{1+e^{-Q(t)}}\left[\mu_{b}(T(t))\right]\left(1-e^{\left(y-y_{\max }\right)}\right),
\end{aligned}
$$

where $\mathrm{y}=\ln ?(\mathrm{x})$ and $\mathrm{Q}=\ln ?(\mathrm{q})$.

The differential forms the primary models, which allowed for prediction under non-isothermal conditions, were solved using numerical methods. Forth order Runge-Kutta method (Kam, 2006) was used to solve first order differential equations in the form of

$$
\frac{d y}{d x}=f(x, y), y(0)=y_{o}
$$

This algorithm discretizes the time domain as

$$
t_{n}=t_{o}+\Delta t \cdot n, \quad \text { for } n=0,1,2, \ldots
$$

and evaluates the function $\mathrm{f}(\mathrm{t}, \mathrm{y}(\mathrm{t}))$ at the beginning, end, and midpoint of each time interval (Amézquita, 2004). A popular solution to the Runge-Kutta forth order algorithm is (Amézquita, 2004, Kam, 2006)

$$
\begin{aligned}
& y_{n+1}=y_{n}+\frac{1}{6}\left(k_{1}+2 k_{2}+2 k_{3}+k_{4}\right) \\
& k_{1}=\Delta t \cdot f\left(x_{n}, y_{n}\right) \\
& k_{2}=\Delta t \cdot f\left(t_{n}+\frac{1}{2} \Delta t, y_{n}+\frac{1}{2} k_{1}\right) \\
& k_{3}=\Delta t \cdot f\left(t_{n}+\frac{1}{2} \Delta t, y_{n}+\frac{1}{2} k_{2}\right) \\
& k_{4}=\Delta t \cdot f\left(t_{n}+\Delta t, y_{n}+k_{3}\right) .
\end{aligned}
$$

Parameters were entered in MATLAB 7.0.1 for estimations of growth over time during a specific temperature profile. RungeKutta forth-order methods were implemented in MATLAB 7.0.1 and the example programs are given in the appendix. The sinusoidal equation chosen was $\mathrm{T}=17.5 \times \sin (2 \pi \times \mathrm{t} / 4)+27.5$. The temperature started at $27.5^{\circ} \mathrm{C}$ then rose to $45^{\circ} \mathrm{C}$ and fell to $10^{\circ} \mathrm{C}$, in 4 $\mathrm{h}$ for five cycles. Three real-life temperature profiles were made using scenarios (Table 1) from microbiological risk assessment model for C. sakazakii from Joint FAO/WHO Expert Meetings on Microbiological Risk Assessment (JEMRA) (http:// www.mramodels.org/ESAK/ default.aspx). Worst case scenarios were chosen to obtain C. sakazakii growth to validate developed models. The temperature profiles were programmed into a commercial software package (NesCom 3.0 Software, Newington, NH) to replicate the desired temperature profile in the water baths (RTE 740, Thermo Neslab, Newington, NH).

\section{Results and discussion}

\section{Protocol}

Growth of C. sakazakii at $8.5^{\circ} \mathrm{C}$ showed ropiness and clumping within the sample, resulting in significant differences in counts between dilutions and within the sample itself. Homogenization of the sample using a stomacher (Seward Model 400, Tekmar 
Company) alleviated the issue and provided more precise enumeration of C. sakazakii.

Subsequently, predictive models for growth of C. sakazakii were validated using a sinusoidal profile. When sampling at lower temperatures, issues related to differences in populations between the dilutions were encountered. Addition of Tween-80 to the initial sample and the use of Tween-80-supplemented diluents in preparation of subsequent dilutions alleviated the issue and consistent counts were observed between duplicate plates. Tween- 80 is a surfactant and emulsifier that can be used as a dispersing agent (Windholz et al., 1983) and allows easier plating and enumeration. Stomaching, warming the sample, and the use of Tween- 80 alleviated the clumping issue, providing consistent results in enumeration of $C$. sakazakii. The growth data for $C$. sakazakii under isothermal temperature profiles were repeated following the new protocol (use of Tween-80 supplemented diluents, warming, and stomaching the sample). Fig. 1 shows the differences in observed growth of C. sakazakii in IMF at $10^{\circ} \mathrm{C}$ using the previous and revised protocols.

No mention of difficulty in accuracy of making dilutions or enumeration has been reported in literature. In most of the literature on C. sakazakii growth, the microbial growth data was not fully disclosed. Richards et al. (2005) incorporated a technique that somewhat resembles stomaching: vigorously shaking the sample containers of formula before drawing $5 \mathrm{~mL}$ aliquots, which were then combined with $45 \mathrm{~mL}$ of Enterobacteriaceae enrichment broth supplemented with nalidixic acid and pyruvate and then subjected to vigorous agitation. This protocol may not be sufficient if $C$. sakazakii has produced the capsular exopolysaccharide, resulting in clumping of the cells, apparently reducing the microbial counts. Our protocol allows for the homogeneity of the formula, clumps of C. sakazakii, and any biofilm formation on the inner wall of the test tubes. Iversen et al. (2004) discussed the ability of $C$. sakazakii to adhere to silicon, latex, and polycarbonate. Neonatal infections associated with brushes, blenders, and spoons (Simmons et al., 1989; BarOz et al., 2001) show the ability of $C$. sakazakii to adhere to surfaces and the enhanced attachment and adherence might be explained by the formation of exopolysaccharide capsular material (Scheepe-Leberkühne and Wagner, 1986). The authors reported that polysaccharide formation occurs within $4 \mathrm{~h}$ at 27 ${ }^{\circ} \mathrm{C}$. They reported that $C$. sakazakii produced an exopolysaccharide which showed extremely high viscosity in solutions and gel formation with trivalent cations. In the present study, it was observed that with addition of Tween- 80 to the sample and stomaching the infant formula, growth data from each temperature profile improved and was not as erratic in

Table 1. Description of temperature abuse profiles created in JEMRA (temperature profiles were slightly altered to allow waterbath to keep up with the time-steps)

\begin{tabular}{llllllc}
\hline Parameters & JEMRA 1 & \multicolumn{3}{c}{ JEMRA2 } & JEMRA3 & Time $(\mathrm{h})$ \\
\cline { 2 - 7 } & Temperature $\left({ }^{\circ} \mathrm{C}\right)$ & Time $(\mathrm{h})$ & Temperature $\left({ }^{\circ} \mathrm{C}\right)$ & Time $(\mathrm{h})$ & Temperature $\left({ }^{\circ} \mathrm{C}\right)$ & 35 \\
\hline Reconstitution (Water) & 30 & & 25 & & 35 & 1 \\
Preparation(Air) & 25 & 1 & 30 & 1 & 30 & 2 \\
Holding(Air) & 10 & 2 & 10 & 1 & 15 & 0.6 \\
Re-warming(Formula) & 45 & 0.5 & 40 & 0.5 & 40 & 4 \\
Feeding(Air) & 30 & 4 & 27 & 4 & 30 & \\
\hline
\end{tabular}

Table 2. Comparison of lag periods of C. sakazakii in reconstituted powdered infant milk formula calculated from each primary model

\begin{tabular}{llllc}
\hline Temperature $\left({ }^{\circ} \mathrm{C}\right)$ & Lag Period $(\mathrm{h})$ & & & Logistic \\
\cline { 2 - 5 } & Observed & Baranyi & Gompertz & 238.59 \\
\hline 8.5 & 155 & 165.38 & 176.06 & 134.76 \\
10 & 75 & 88.07 & 98.56 & 23.04 \\
15 & 8 & 9.43 & 12.16 & 8.55 \\
20 & 2 & 2.79 & 3.58 & 4.95 \\
25 & 1 & 1.76 & 1.84 & 2.69 \\
28 & 1 & 0.65 & 0.90 & 2.29 \\
32 & 1 & 0.54 & 0.86 & 1.95 \\
35 & 0.5 & 0.51 & 0.63 & 1.83 \\
37 & 0.5 & 0.51 & 0.72 & 1.31 \\
40 & 0.5 & 0.26 & 0.42 & 1.85 \\
42 & 0.5 & 0.48 & 0.85 & 1.87 \\
45 & 1 & 0.64 & 0.79 & 0.60 \\
47 & 3 & 0.53 & -0.04 & \\
\hline
\end{tabular}


Fig. 1. Comparison of growth results of $C$. sakazakii in reconstituted powdered infant milk formula at $10^{\circ} \mathrm{C}$ (" Old Protocol, ‘ \%' New Protocol with Tween-80)

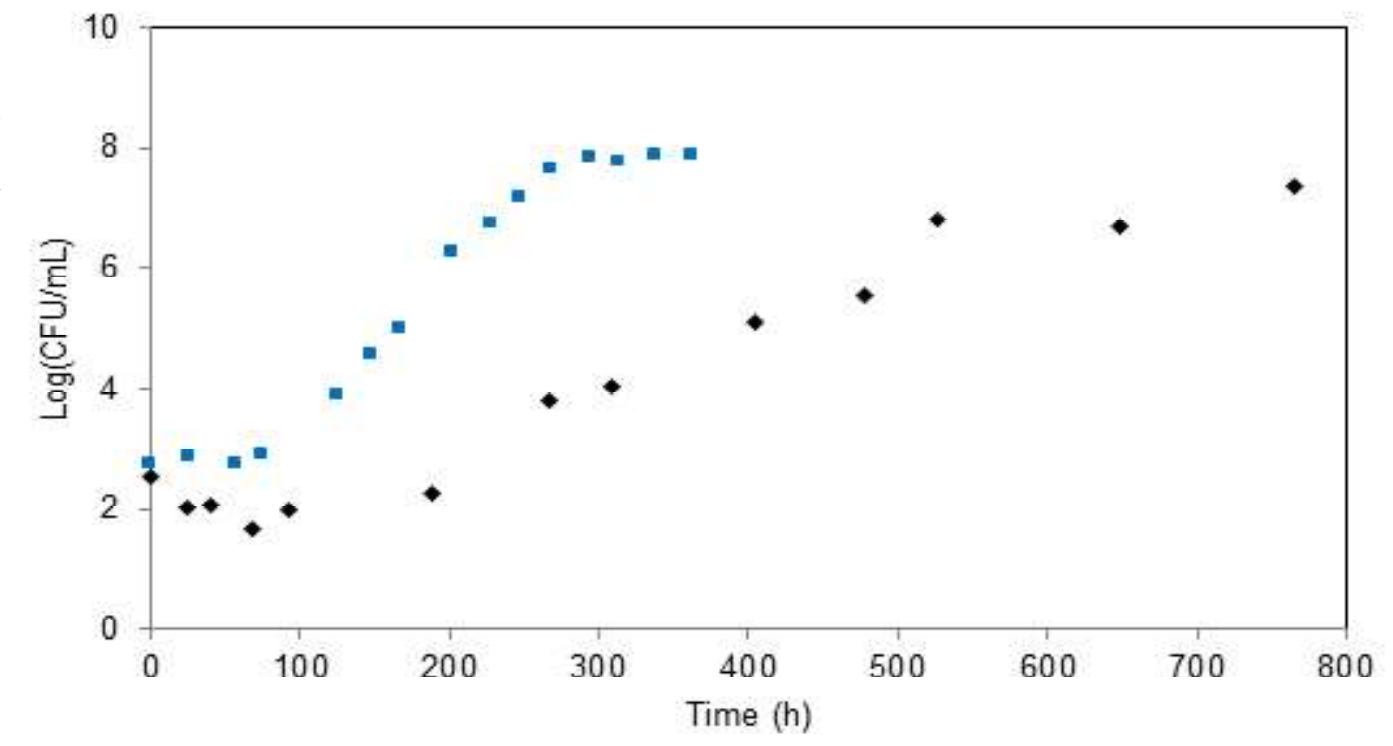

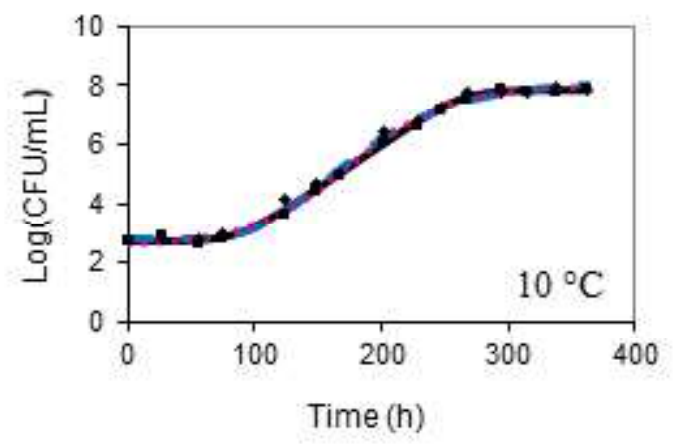
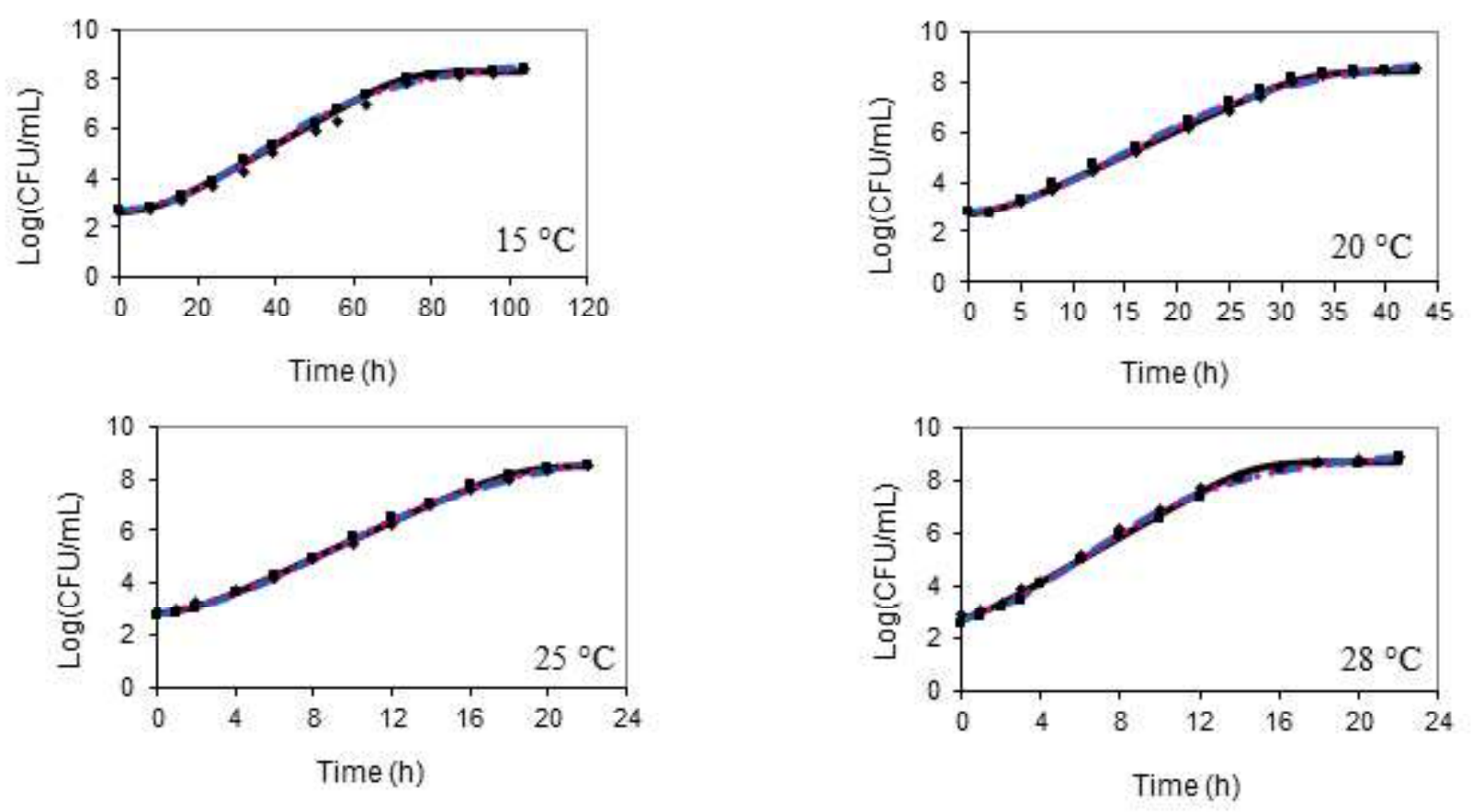

Fig. 2. Primary model results for the growth of E. sakazakii in reconstituted powdered infant milk formula (' $\bullet$ 'Rep 1, ' \%' Rep 2, '-' Baranyi, '--_' Gompertz, '- - -' Logistic) 
enumeration compared to the growth data generated using the previous protocol.

\section{Primary models}

Figs. 2 - 3 show the predicted and observed C. sakazakii growth profiles in IMF at various temperatures. For each primary model, predicted growth followed the observed growth well for both infant milk and soy formula. Table 2 and 3 show the lag periods and generation times calculated from each primary model. Calculating the lag periods from Gompertz parameters provided several negative values, which were obviously incorrect. A disadvantage of the Gompertz model is that the slope cannot be zero and because of the lower asymptote of the sigmoid curve must be below the initial inoculum concentration, which can result in the duration of the lag phase to be negative (Baranyi et al., 1993). Lag periods calculated using the Baranyi equation matched the observed lag periods well except for values for ISF at $20{ }^{\circ} \mathrm{C}$. At $47{ }^{\circ} \mathrm{C}$, all models under-predicted the lag period for IMF. Overall, the lag period was slightly higher in IMF than in ISF.

Kandhai et al. (2006) reported lag times of $83.3 \pm 18.7$ and $1.73 \pm$ $0.43 \mathrm{~h}$ at $\mathrm{H} " 10$ and $37^{\circ} \mathrm{C}$, respectively. In the present study lag times of 88 and $74 \mathrm{~h}$, at $10^{\circ} \mathrm{C}$ was calculated in IMF and ISF, respectively. At 10 and $20^{\circ} \mathrm{C}$, the generation times from Baranyi parameters were $10.4 \mathrm{~h}$ and $1.5 \mathrm{~h}$, respectively in IMF. Iversen and Forsythe (2003) reported at 10 and $21^{\circ} \mathrm{C}$, the generation times were 10 and $1.25 \mathrm{~h}$, respectively. Iversen and Forsythe (2004) reported generation times of 14 and $0.75 \mathrm{~h}$ at $10^{\circ} \mathrm{C}$, and room temperature, respectively. Nazarowec-White and Farber (1997) reported generation times of 0.67 and $4.18 \mathrm{~h}$ at 23 and $10^{\circ} \mathrm{C}$ in infant formula.

\section{Secondary models}

Fig. 4 and 5 show the predicted and observed $C$. sakazakii growth rates as a function of temperature. The Ratkowsky (secondary) model from Baranyi model parameters showed a slightly higher C. sakazakii growth rate in IMF compared to ISF. Ratkowsky models developed from Gompertz and Logistic primary models showed similar growth rates between IMF and ISF.

To limit over-prediction at optimum temperatures, the $\mu_{\mathrm{opt}}$ parameter in SAS was bound to be less than $2.1 \mathrm{~h}^{-1}$ for IMF and less than $1.8 \mathrm{~h}^{-1}$ for ISF in the Gamma-Baranyi model. Without bounds in SAS, Gamma models from Gompertz and Logistic followed the observed values very well and did not over-predict. Table 4 shows the measurements of bias and accuracy factors

Table 3. Comparison of generation periods of $C$. sakazakii in reconstituted powdered infant milk formula calculated from each primary model

\begin{tabular}{lllc}
\hline Temperature $\left({ }^{\circ} \mathrm{C}\right)$ & \multicolumn{2}{c}{ Generation period $(\mathrm{h})$} & Logistic \\
\cline { 2 - 4 } & Baranyi & Gompertz & 10.34 \\
\hline 8.5 & 17.33 & 15.34 & 6.07 \\
10 & 10.38 & 8.72 & 2.05 \\
15 & 3.39 & 2.94 & 0.94 \\
20 & 1.55 & 1.35 & 0.54 \\
25 & 0.88 & 0.80 & 0.42 \\
28 & 0.70 & 0.60 & 0.30 \\
32 & 0.51 & 0.43 & 0.26 \\
35 & 0.43 & 0.38 & 0.24 \\
37 & 0.39 & 0.34 & 0.22 \\
40 & 0.36 & 0.31 & 0.20 \\
42 & 0.34 & 0.29 & 0.23 \\
47 & 0.38 & 0.34 & 0.72 \\
\hline
\end{tabular}

Table 4. Measurements of bias and accuracy factors for ?max in reconstituted powdered infant milk and soy formula

\begin{tabular}{lllll}
\hline Secondary Model & Milk & & Soy & $\mathrm{A}_{\mathrm{f}}$ \\
\cline { 2 - 4 } & $\mathrm{B}_{\mathrm{f}}$ & $\mathrm{A}_{\mathrm{f}}$ & $\mathrm{B}_{\mathrm{f}}$ & 1.3702 \\
\hline Ratkowsky-Baranyi & 1.1239 & 1.1879 & 1.2390 & 1.1033 \\
Ratkowsky-Gompertz & 0.9186 & 1.1894 & 0.9701 & 1.1577 \\
Ratkowsky-Logistic & 0.8891 & 1.2573 & 0.9396 & 1.5213 \\
Gamma-Baranyi & 1.0645 & 1.1155 & 1.2585 & 1.3532 \\
Gamma-Gompertz & 0.9672 & 1.1046 & 0.8867 & 1.1710 \\
Gamma-Logistic & 0.9958 & 1.0445 & 0.9448 & \\
\hline
\end{tabular}



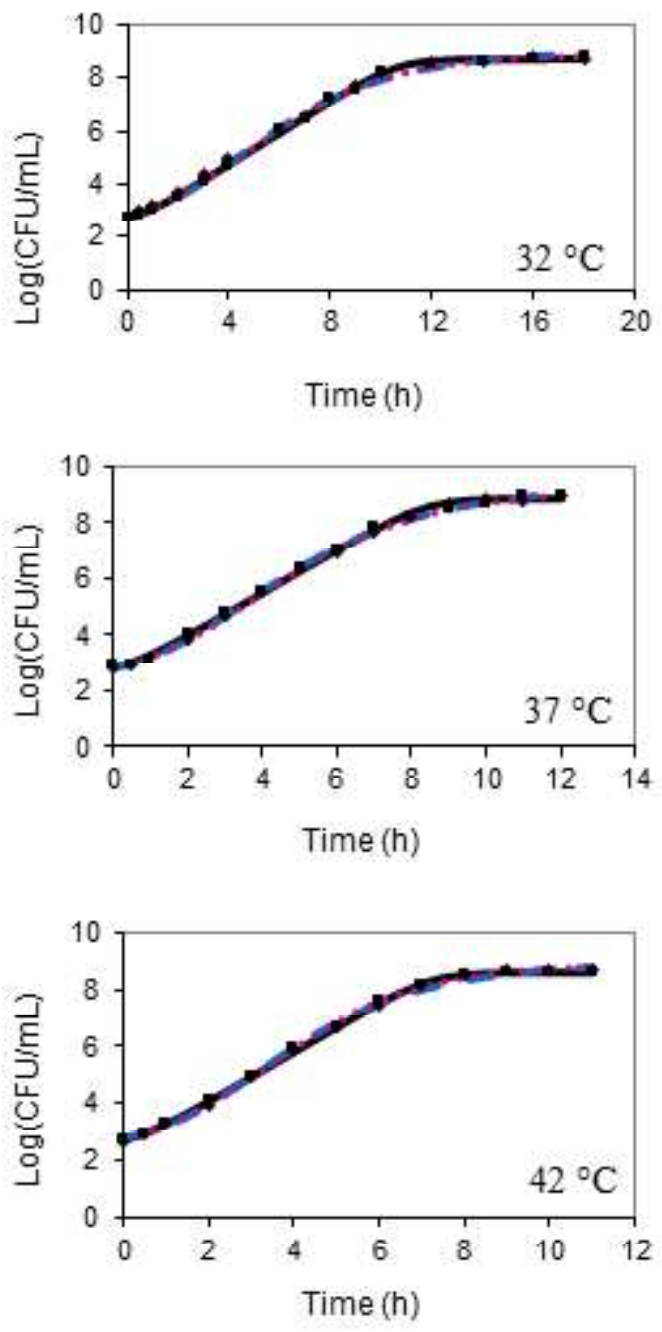

Fig. 3. Primary model results for the growth of E. sakazakii in reconstituted powdered infant milk formula (' ' Rep 1, ‘ \%' Rep 2, '-' Baranyi, '--_' Gompertz, '- - -' Logistic)

for $\mu_{\max }$ in reconstituted powdered infant milk and soy formula. When there is a perfect agreement between the predicted and observed values, the bias and accuracy factors equal 1 (Tamplin et al. 2005).

Jo et al. (2010) developed models for $C$. sakazakii in IMF using four temperatures: $10,20,30$, and $40^{\circ} \mathrm{C}$. Fig. 6 shows the differences between Jo et al. (2010) secondary model against our secondary models. By not modeling the entire temperature range at which
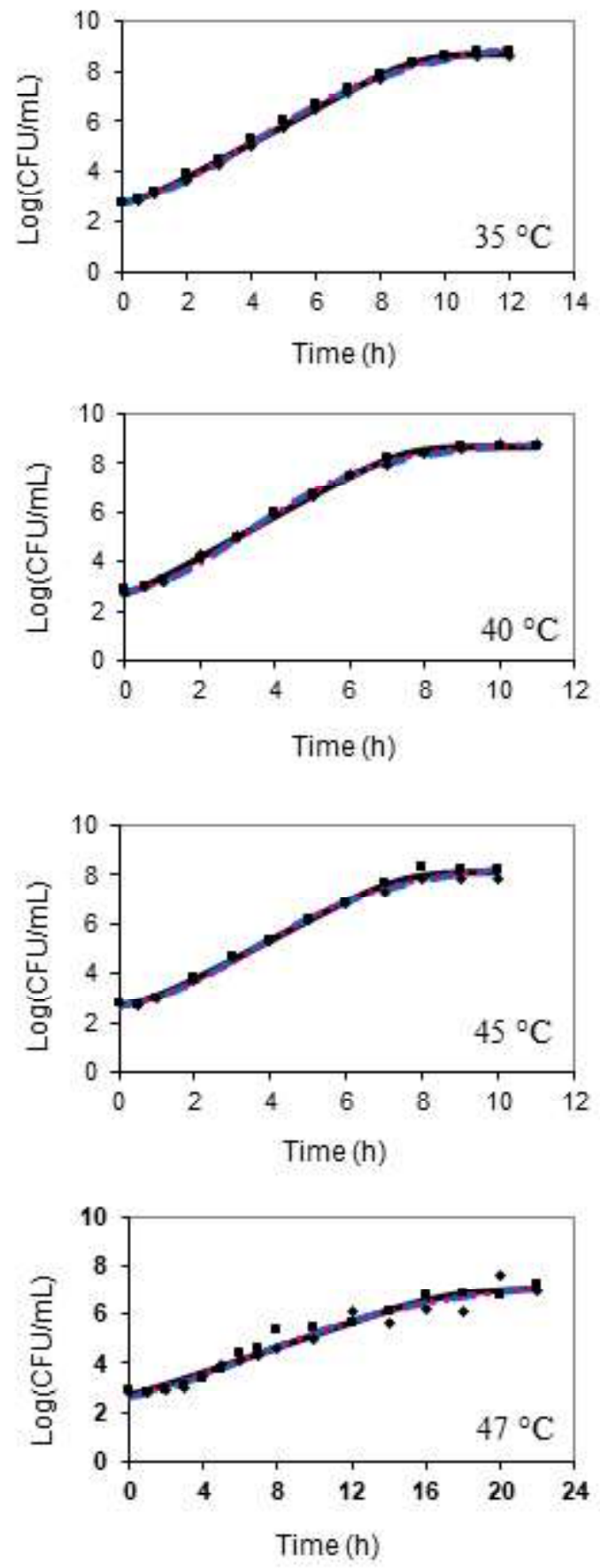

the organism grows, Jo et al. (2010) secondary model does not curve downward after passing the optimum growth temperature.

Iversen et al. (2004) reported optimum temperatures of $37-43^{\circ} \mathrm{C}$ for growth of C. sakazakii, which were consistent with the findings in this study for both infant milk and soy formula. Iversen et al. (2004) reported a mean specific growth rate of $2.88 \mathrm{~h}^{-1}$ at 40 ${ }^{\circ} \mathrm{C}$ for IMF. In the present study, the observed maximum specific growth rates were 1.87 and $2.1 \mathrm{~h}^{-1}$ (IMF) and 1.7 and $1.8 \mathrm{~h}^{-1}$ (ISF) for 40 and $42{ }^{\circ} \mathrm{C}$, respectively. 
Fig. 4. Ratkowsky model (from Baranyi parameters) results of the maximum specific growth rate of $C$. sakazakii in re c o n s t it u t ed powdered infant formula (' ' Milk Observed, '-' Milk Predicted, ' \%' Soy Observed, 'Soy Predicted)

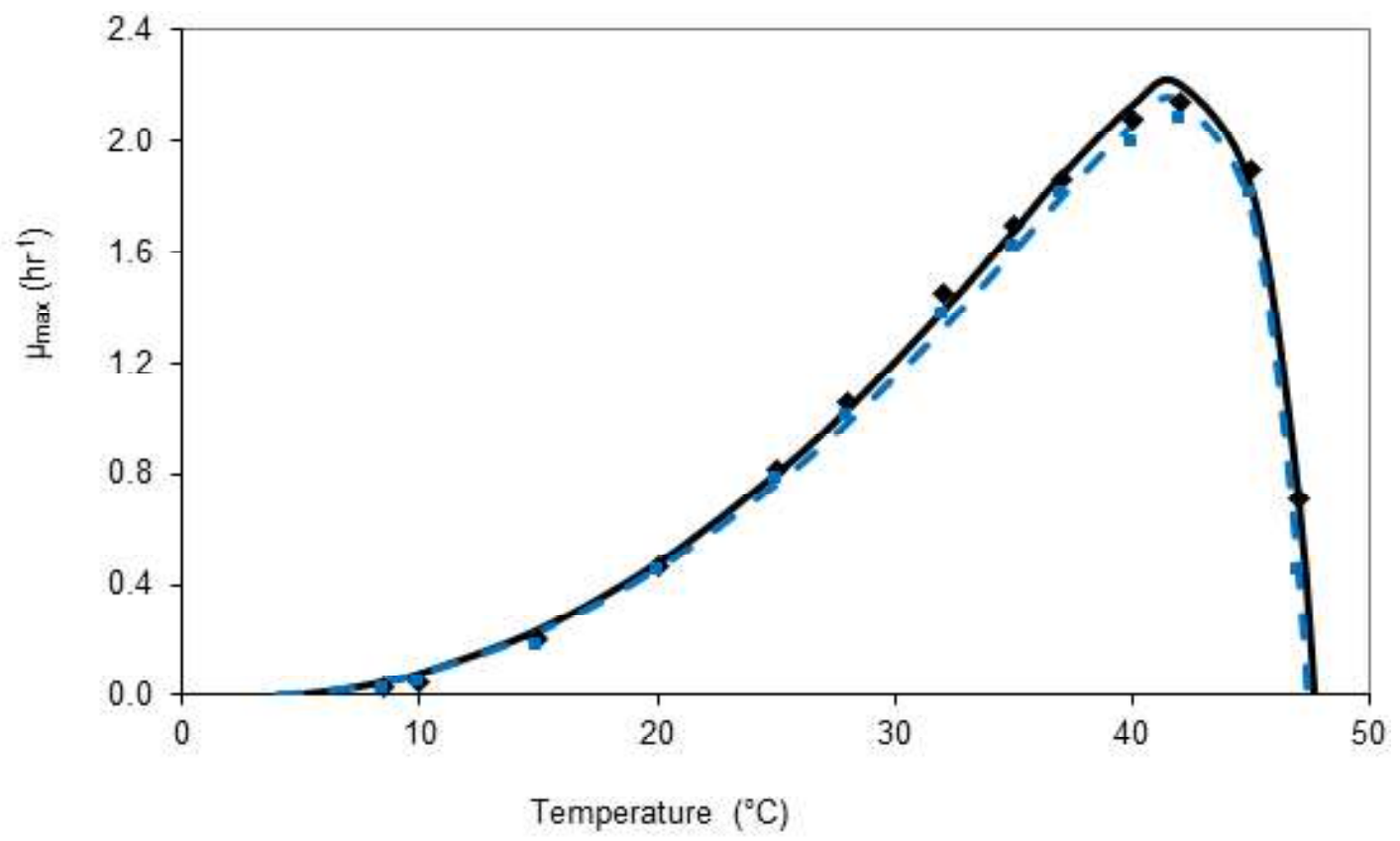

Fig. 5. Gamma model (from Baranyi parameters) results of the maximum specific growth rate of $C$. sakazakii in reconstituted powdered infant formula (" Milk Observed, '-_' Milk Predicted, '\%' Soy

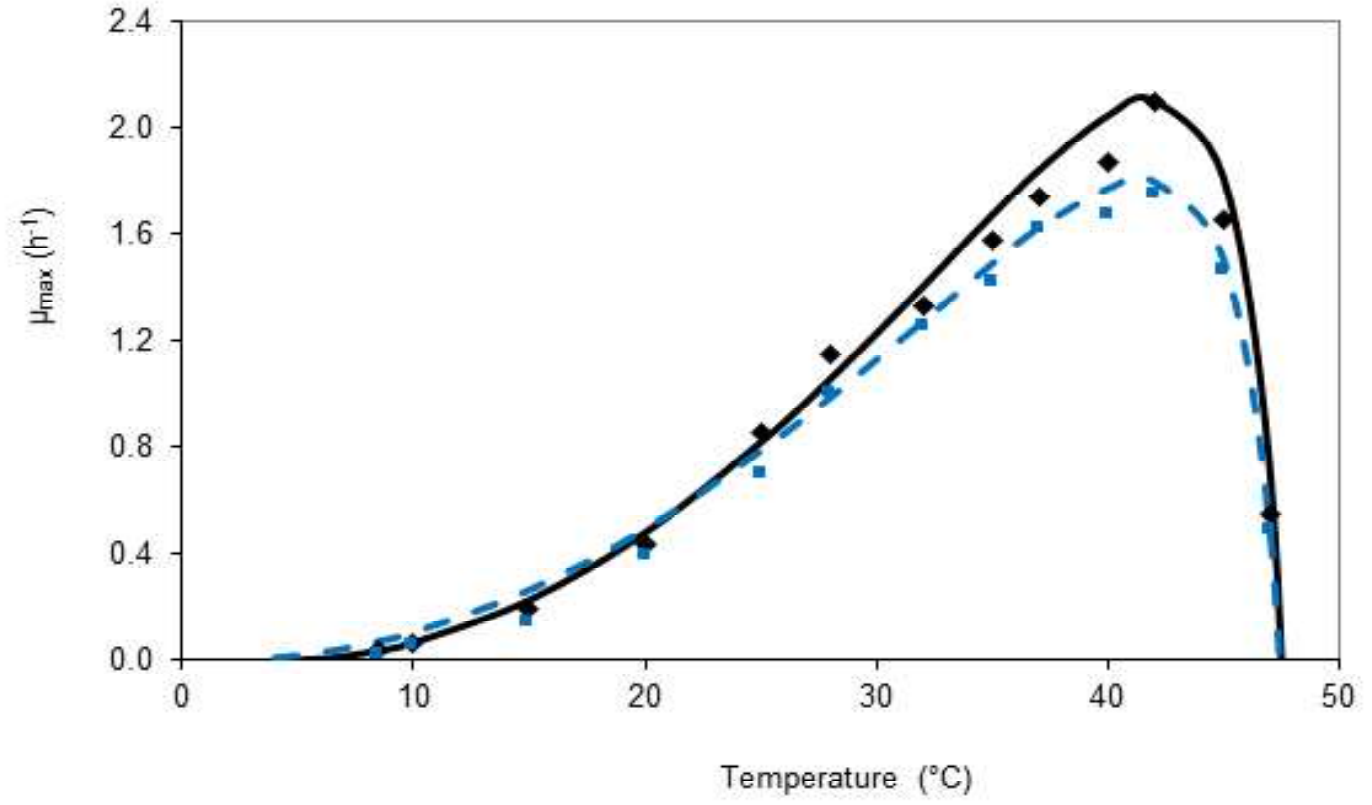

\section{Dynamic models}

Tables 5 and 6 show the RMSE values $(\log \mathrm{CFU} / \mathrm{mL})$ for the dynamic models that were validated in the laboratory. Figs. 7 - 10 show the predicted and observed growth of C. sakazakii during two of the non-isothermal temperature profiles that were validated in the laboratory for IMF and ISF. The dynamic model allows the user to input isothermal temperature profiles, therefore going back to the primary model for static temperature predicted growth is not needed. For temperatures between 20 and $45^{\circ} \mathrm{C}$, the dynamic models from Baranyi models predicted well when integrated with 
Fig. 6. Comparison $r_{\max }$ values against Jo and et al., (2010) values Observed, '_-' $\mathrm{R}$ a $\mathrm{t} \mathrm{k}$ o w s k y Gompertz, '--' Gamma-Gompertz, ' $2 \%$ ' Jo and et al., (2010) Observed, '- ', Jo and et al., (2010) Predicted)

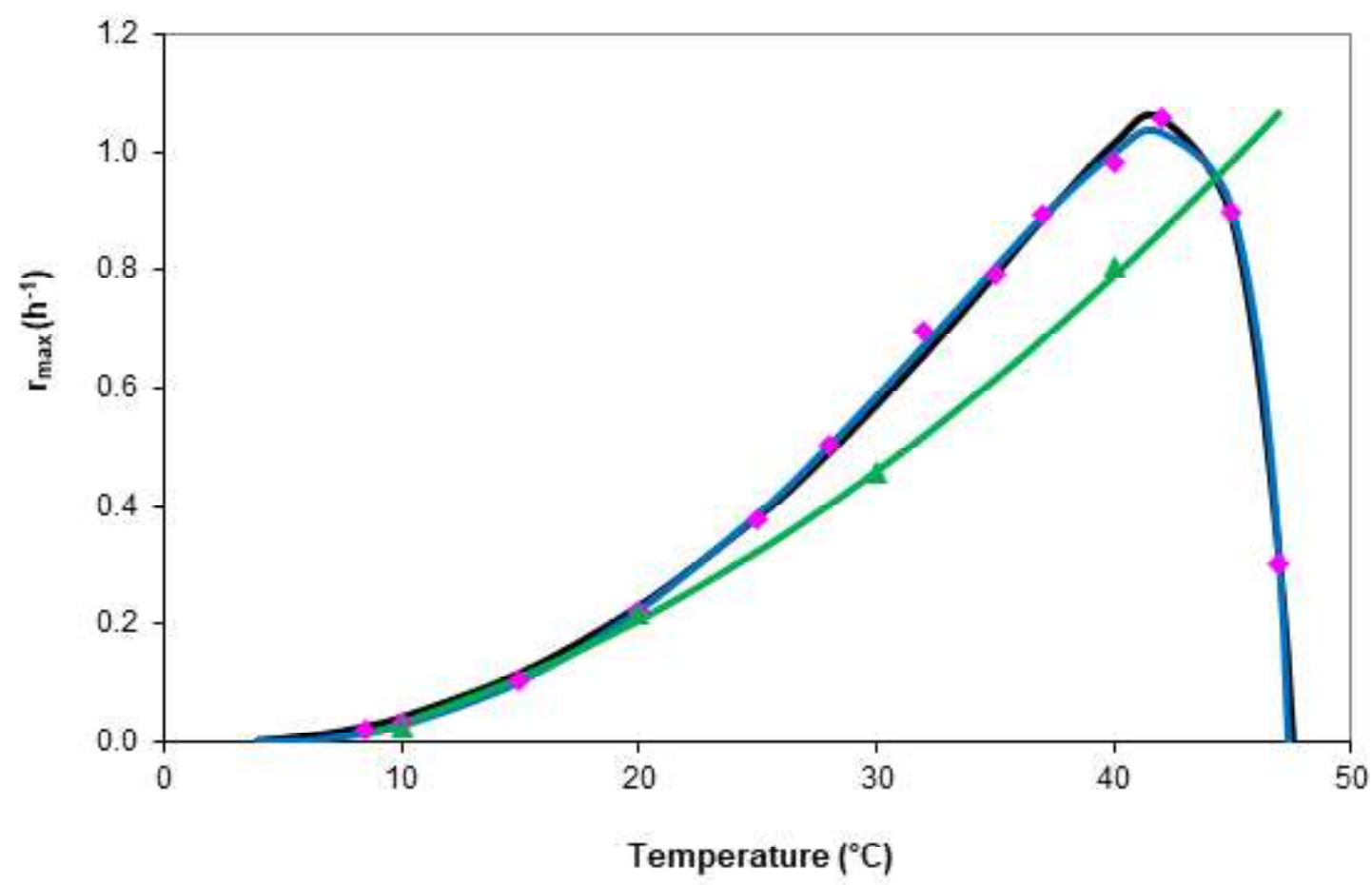

Table 5. RMSE values ( $\log \mathrm{CFU} / \mathrm{mL}$ ) for the dynamic models for non-isothermal temperature validations

\begin{tabular}{llllr}
\hline Formula & Temperature Profile & Gamma & & Logistic \\
\cline { 2 - 4 } & & Baranyi & Gompertz & 0.45 \\
Milk & Sinusoidal & 0.23 & 0.74 & 0.34 \\
& JEMRA 1 & 0.25 & 0.83 & 0.39 \\
& JEMRA 2 & 0.20 & 0.91 & 0.12 \\
Soy & JEMRA 3 & 0.25 & 0.69 & 0.71 \\
& Sinusoidal & 0.40 & 0.96 & 0.22 \\
& JEMRA 1 & 0.28 & 0.61 & 0.19 \\
& JEMRA 2 & 0.16 & 0.66 & 0.13 \\
\hline
\end{tabular}

Table 6. RMSE values $(\log \mathrm{CFU} / \mathrm{mL})$ for the dynamic models for non-isothermal temperature validations

\begin{tabular}{llllr}
\hline Formula & Temperature Profile & Ratkowsky & & Lompertz \\
\cline { 2 - 4 } & & Baranyi & 0.61 & 0.79 \\
\hline Milk & Sinusoidal & 0.29 & 0.59 & 0.61 \\
& JEMRA 1 & 0.49 & 0.47 & 0.46 \\
& JEMRA 2 & 0.19 & 0.56 & 0.43 \\
Soy & JEMRA 3 & 0.26 & 0.67 & 0.71 \\
& Sinusoidal & 0.29 & 0.62 & 0.44 \\
& JEMRA 1 & 0.25 & 0.46 & 0.25 \\
& JEMRA 2 & 0.14 & 0.65 & 0.38 \\
\hline
\end{tabular}

Ratkowsky, but slightly under-predicted when integrated with Gamma.

When predicting at lower temperatures and $47^{\circ} \mathrm{C}$, the dynamic models over-predicted C. sakazakii growth in infant milk and soy formula. The $h_{0}$ values were fixed at the average which would explain the over-prediction at the lower temperatures. The value reflects the lag period; therefore a smaller indicates a shorter lag period. For the modified Gompertz model, the curvature in the exponential phase tends to over-estimate the maximum specific 
Fig. 7. Validation growth results of $C$. sakazakii in $\mathrm{r}$ e c o n s t i t u t e d powdered infant milk formula (Ratkowsky integrated with primary models) (' ' Rep 1, ‘\%” Rep 2, '—' Baranyi, ‘- -' Gompertz, '. - .' Logistic, '- - . - - ' Temperature)

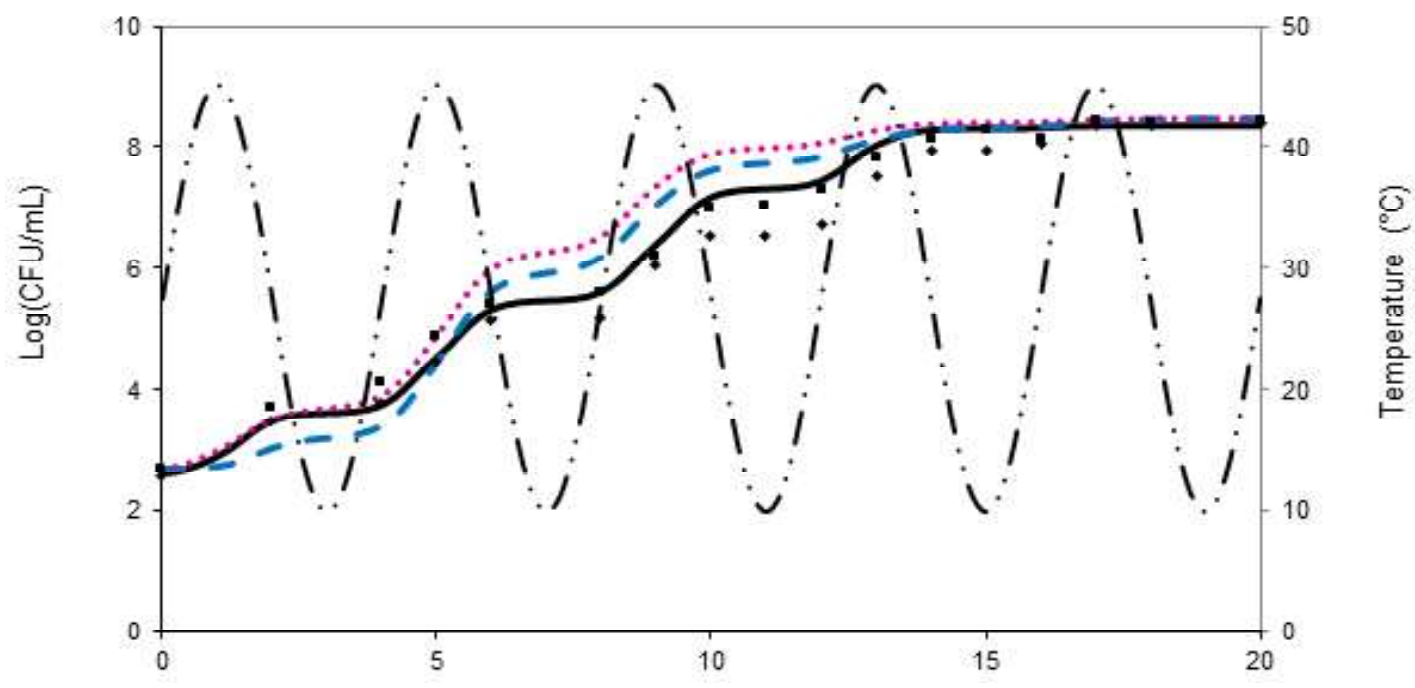

Time (h)

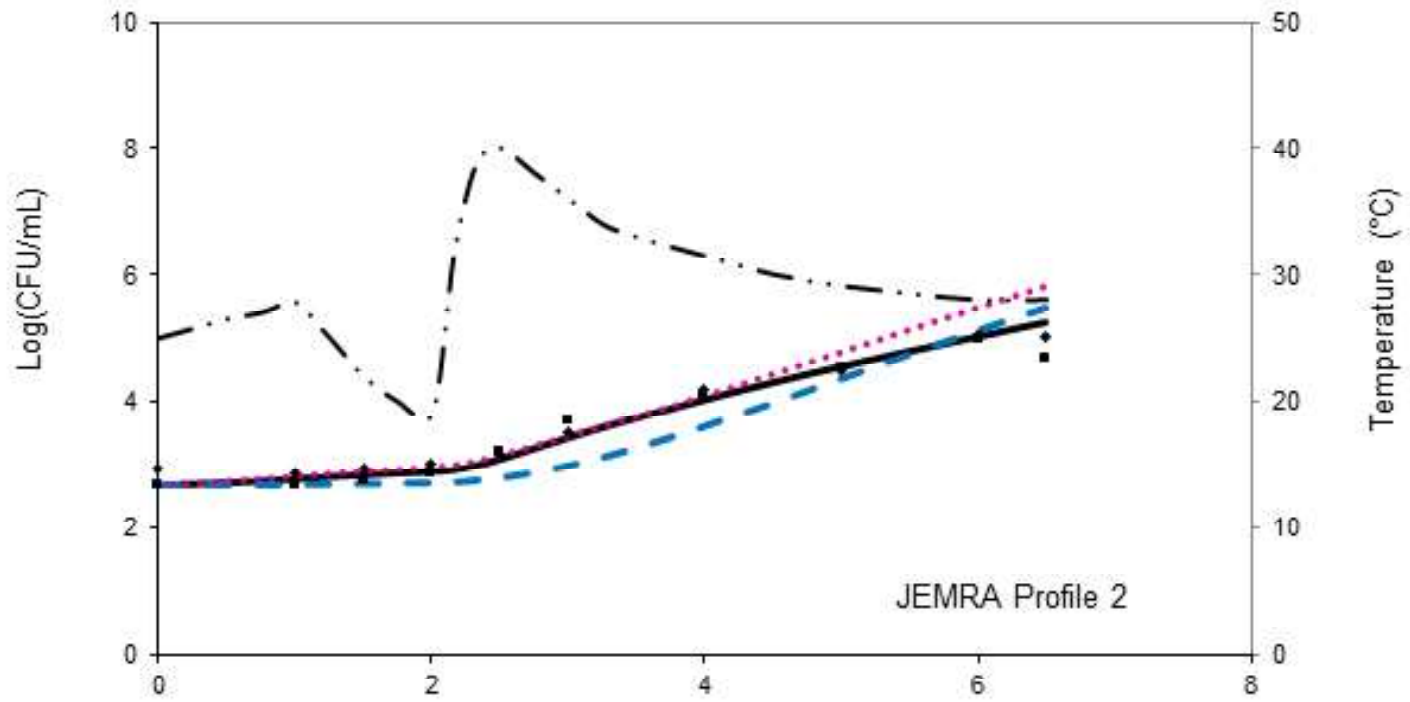

Time (h)
Fig. 8. Validation growth results of $C$. sakazakii in recons tituted powdered infant milk formula (Ratkowsky integrated with primary models) (' Rep 1, ' \%' Rep 2, '_' Baranyi, '- _ -' Gompertz, ' - . -' Logistic, '-- - - - ' Temperature)

\section{in}


Fig. 9. Validation growth results of $C$. sakazakii in re c o n s tituted powdered infant milk formula (Gamma integrated with primary models) (' Rep 1, '\%' Rep 2, '—' Baranyi, '- - -' Gompertz, ' - - -' Logistic, '- - - - - ' Temperature)

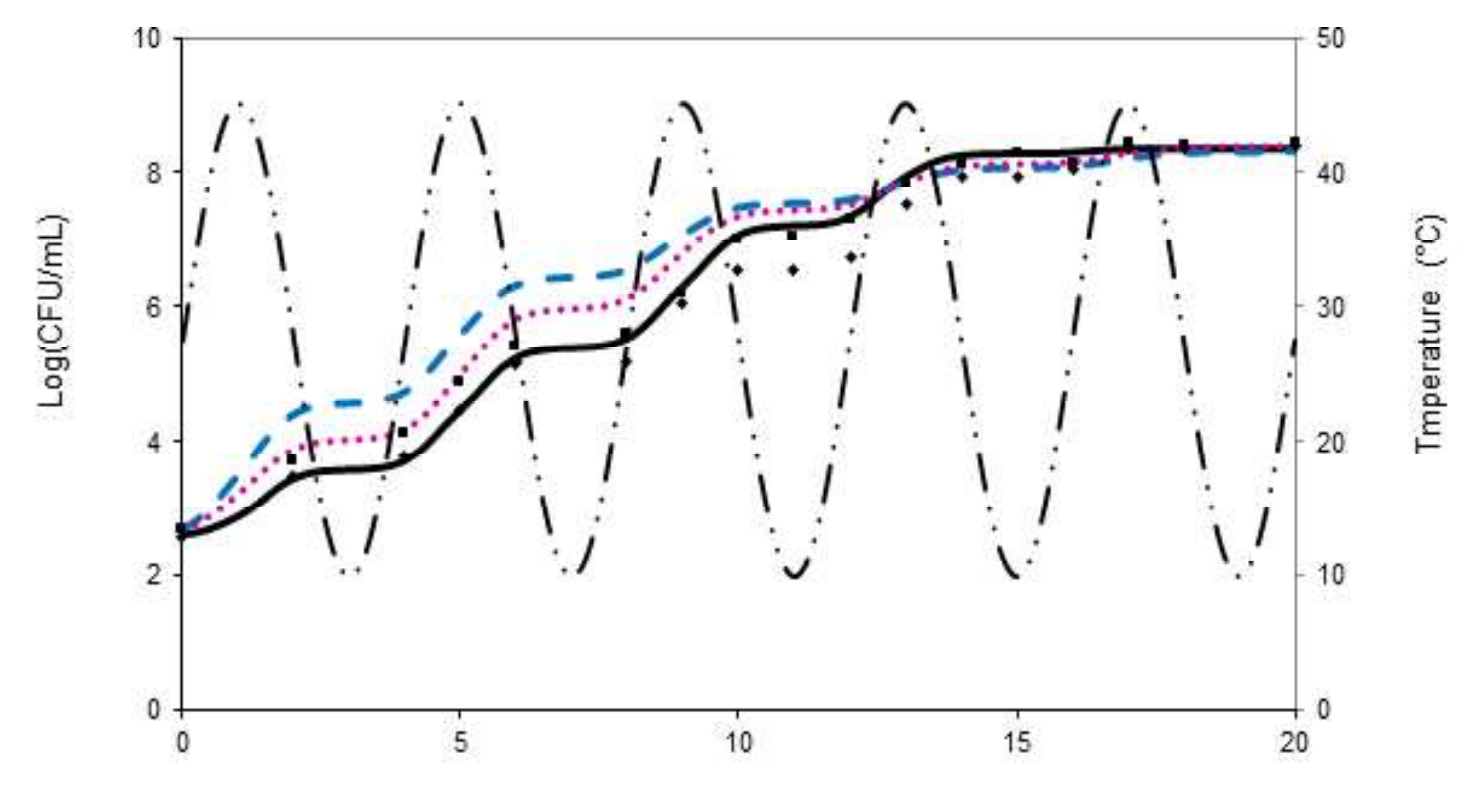

Time (h)

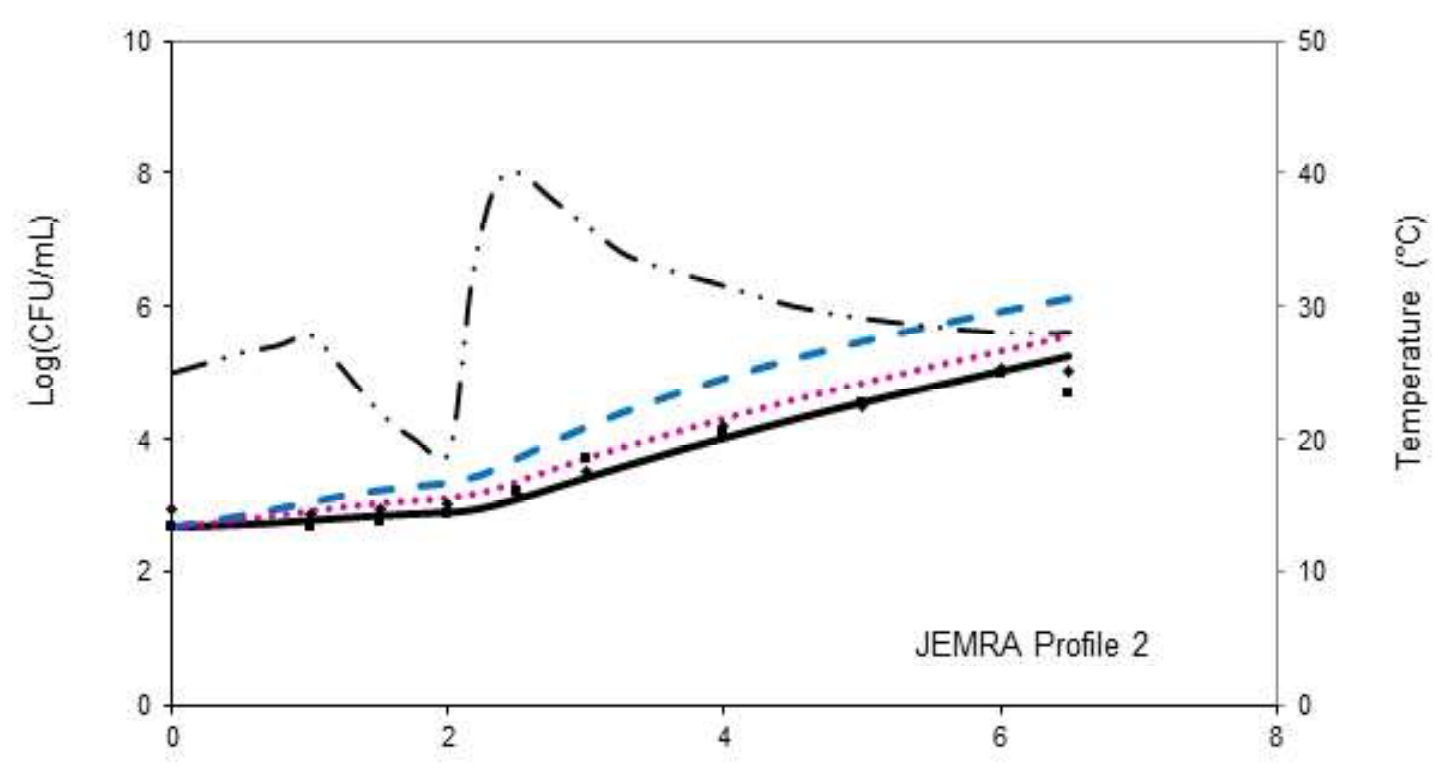

Tlme (h)
Fig. 10. Validation growth results of $C$. sakazakii in reconstituted powdered infant milk formula (Gamma integrated with primary models) (' ' Rep 1, '\%' Rep 2, '--' Baranyi, '- - ', Gompertz, '- . -' Logistic, 'Temperature) models over-predicts during these temperature-abuse profiles when integrated with Gamma but under-predicts when integrated with Ratkowsky. Dynamic models from Logistic models follow pretty well with some slight over-predictions towards the end of the temperature profile.

From the results of the validations, the dynamic models best suited for prediction of growth under temperature varying conditions would be the Baranyi and Logistic models integrated with the Ratkowsky model. By having both sets of results, a range of growth could be analyzed for the potential growth of $C$. sakazakii for a particular temperature profile. Rosset et al. (2007) reported temperature profiles of the infant formula during preparation and feeding to the infants. These temperature profiles were used to evaluate growth using the dynamic models, with initial populations of $1 \mathrm{CFU} / \mathrm{mL}$ (Muytjens et al., 1988). For the first feeding and manufacturing profiles, carefully following preparation guidelines minimizes growth of C. sakazakii (log 
$\mathrm{CFU} / \mathrm{mL}$ or $\mathrm{g}$ ). The last feeding temperature profile resulted in the prediction of 0.5 and $1.5 \log$ CFU/mL growth for the Ratkowsky model integrated with Baranyi and Logistic models, respectively. Even if the Ratkowsky-Logistic dynamic model over-predicts, by having both dynamic models, a range of potential growths can be predicted. If proper protocols are followed, inhibition of growth should be expected. On the other hand, if higher contamination levels already exist because of improper cleaning or handling, or if temperature abuse occurs, growth of $C$. sakazakii to unacceptable levels should be expected. Also, cross-contamination should be addressed. Even if contamination levels are as low as $1 \mathrm{CFU} / 100 \mathrm{~g}$ in the PIF, cross-contamination of the reconstituted PIF could easily result in outbreaks. If equipment is not cleaned properly like in past outbreaks, following proper preparation protocols would not prevent outbreaks.

Telang et al. (2005) concluded that C. sakazakii counts from infant formula for inoculated preterm formula or inoculated human milk samples, unfortified or fortified, did not increase significantly over $6 \mathrm{~h}$. Under ideal preparation conditions leaving out formula for $6 \mathrm{~h}$ might not result in significant growth, but as stated above, cross-contamination or temperature abuse could result in an illness. To address the potential risk of non-trained hospital workers, the risk of leaving reconstituted PIF at room temperature, using JEMRA and parameters from FAO/WHO (2006), a temperature profile was generated to depict a preparation scenario that includes a $6 \mathrm{~h}$ hang-time. With different preparation recommendations for tube feeding, the temperature profile could include a re-warming step that allows for 15 min heating in a water-bath set at $37^{\circ} \mathrm{C}$. Reconstitution temperature and ambient room temperature were set at $25^{\circ} \mathrm{C}$. FAO/WHO (2006) stated that a NICU could have a room temperature of up to $35^{\circ} \mathrm{C}$, which was inputted into JEMRA's risk model parameters as the ambient room temperature during the $6 \mathrm{~h}$ hang-time. The RatkowskyBaranyi dynamic model resulted in prediction of $4 \log \mathrm{CFU} / \mathrm{mL} C$. sakazakii growth in IMF and ISF. The Ratkowsky-Logistic dynamic model predicted C. sakazakii growth to $7 \log \mathrm{CFU} / \mathrm{mL}$. The difference of these two predictions could be explained by the tendency of the Ratkowsky-Logistic dynamic model to overpredict.

\section{Conclusions}

All of the primary models predict $C$. sakazakii growth in infant milk and soy formula very well compared to the observed growth. Secondary models predict the maximum specific growth rates of C. sakazakii well with some slight over-prediction by the Ratkowsky model at higher temperatures. The Gompertz dynamic models resulted in considerable variation in predicted $C$. sakazakii growth. The models that proved to be accurate in predicting the growth of C. sakazakii in reconstituted PIF were Baranyi and logistic primary models integrated with the Ratkowsky secondary model. Although the Ratkowsky-logistic dynamic model predicts higher growth in some instances, this could be the upper limit of growth and the user could evaluate a range of growth on the risk to the infants.

With the infectious dose still uncertain and when dealing with already seriously ill infants, serious concern should be taken to develop recommendations for preparation and handling of PIF subsequent to preparation. There are so many variables from temperature abuse and different ambient room temperatures to extremely busy hospital personnel making seemingly simple mistakes that could result in significant growth of $C$. sakazakii in reconstituted PIF.

There seems to be a lot of controversy about the interpretation of 'level of contamination', 'probability of ingestion', 'single cell' ingestion, infectious dose, etc (Havelaar and Zwietering, 2004; Iversen and Forsythe, 2003; Iversen and Forsythe, 2004). Iversen and Forsythe (2004) stated: "To argue whether it takes $13 \mathrm{~h}$ or $17.9 \mathrm{~h}$ at $21^{\circ} \mathrm{C}$ to reach a particular cell number is missing the point; rehydrated infant milk formula should not be left at $21{ }^{\circ} \mathrm{C}$ for a long period of time - that's temperature abuse". Biering et al. (1989) showed that $C$. sakazakii seemed to be present in the milk powder in low numbers, which would not result in these infections. The authors reported that the rules pertaining to the handling to the formula in the pediatric and NICU units were not always adhered to and that the formula was occasionally kept at $35-37^{\circ} \mathrm{C}$ for extended periods of time in bottle heaters.

The focus should be equally on preparation and sanitation, if not more than the models, because these models cannot predict efficiently if preparation and sanitation rules are not followed. With these problems taken more seriously, these predictive models will be an important asset in risk analysis.

\section{References}

Amézquita A, Weller CL, Wang L, Thippareddi H, Burson DE (2005) Development of an integrated model for heat transfer and dynamic growth of Clostridium perfringens during the cooling of cooked boneless ham. International Journal of Food Microbiology 101, $123-144$

Arseni, A, Malamou-Ladas E, Koutsia C, Xanthou M, Trikka E (1987) Outbreak of colonization of neonates with Enterobacter sakazakii. Journal of Hospital Infection 9, 143-150

Baranyi, J, McClure PJ, Sutherland JP, Roberts TA (1993a) Modeling bacterial growth responses. Journal of Industrial Microbiology 12, 190-194

Baranyi, J, Roberts TA (1994) A dynamic approach to predicting bacterial growth in food. International Journal of Food Microbiology 23: 277-294

Baranyi J, Roberts TA, McClure PJ (1993b) A non-autonomous differential equation to model bacterial growth. Food Microbiology 10: 43-59

Bar-Oz B, Preminger A, Peleg O, Block C, Arad I (2001) Enterobacter sakazakii infection in the newborn. Acta Paediatrica 90: 356-358

Biering G, Karlsson S, Clark NVC, Jonsdottir KE, Ludvigsson P, Steingrimsson O (1989) Three cases of neonatal meningitis caused by Enterobacter sakazakii in powdered milk. Journal of Clinical Microbiology 27: 2054-2056 
Dupont A, Thamdrup, E (1956) Neonatal meningitis: investigations of sources and routes of infection. Danish Medical Bulletin 3: 6-14

FAO/WHO (2006) Expert meeting on Enterobacter sakazakii and Salmonella in powdered infant formula: Meeting report, Microbiological Risk Assessment Series 10

Farmer JJ, Asbury MA, Hickman FW, Brenner DJ (1980) Enterobacter sakazakii: new species of "Enterobacteriaceae" isolated from clinical specimens. International Journal of Systematic Bacteriology 30: 569-584

Ferrieri P (1990) Scope of the problem: neonatal susceptibility and immunity to major bacterial pathogens. Reviews of Infectious Diseases 12: S394-S400

Gibson AM, Bratchell N, Roberts TA (1987) The effect of sodium chloride and temperature on the rate and extent of growth of Clostridium botulinum type A in pasteurized pork slurry. Journal of Applied Bacteriology 62: 479-490

Gibson AM, Bratchell N, Roberts TA (1988) Predicting microbial growth: growth responses of salmonellae in a laboratory medium as affected by $\mathrm{pH}$, sodium chloride and storage temperature. International Journal of Food Microbiology 6: 155-78

Havelaar AH, Zwietering M (2004) On the risk of Enterobacter sakazakii in infant milk formula. Trends in Food Science and Technology 15: 99-100

Himelright I, Harris E, Lorch V, Anderson M (2002) Enterobacter sakazakii infections associated with the use of powdered infant formula Tennessee, 2001. Journal of the American Medical Association 287: 2204-2205

Huang L (2003) Dynamic computer simulation of Clostridium perfringens growth in cooked ground beef. International Journal Food Microbiology 87: 217-227

Iversen C, Forsythe S (2003) Risk profile of Enterobacter sakazakii, an emergent pathogen associated with infant milk formula. Trends in Food Science and Technology 14: 443-454

Iversen C, Forsythe S (2004) Response to 'On the risk of Enterobacter sakazakii in infant milk formula'. Trends in Food Science and Technology 15: 101-102

Iversen C, Lane M, Forsythe SJ (2004) The growth profile, thermotolerance and biofilm formation of Enterobacter sakazakii grown in infant formula milk. Letters in Applied Microbiology 38: 378-382

Iversen C, Mullane N, McCardell BD, Tall B, Lehner A, Fanning S, Stephan R, Joosten H (2008) Cronobacter gen. nov., a new genus to accommodate the biogroups of Enterobacter sakazakii, and proposal of Cronobacter sakazakii gen. nov., comb. nov., Cronobacter malonaticus sp. nov., Cronobacter turicensis sp. nov., Cronobacter muytjensii sp. nov., Cronobacter dublinensis sp. nov., Cronobacter genomospecies 1, and of three subspecies, Cronobacter dublinensis subsp. dublinensis subsp. nov., Cronobacter dublinensis subsp. lausannensis subsp. nov. and Cronobacter dublinensis subsp. lactaridi subsp. nov. International Journal of Systematic and Evolutionary Microbiology 58: 1442-1447

Jeyamkondan S, Jayas DS, Holley RA (2001) Microbial growth modeling with artificial neural networks. International Journal of Food Microbiology 64:343-354

Jo SH, Heo SK, Ha SD (2010) Development of a predictive model describing the growth of Cronobacter sakazakii in reconstituted powdered infant milk formula. Journal of Food Safety 30: 83-93

Kam AK (2006) An interactive e-book for illustrating Runge-Kutta 4th Order Method of solving ordinary differential equations. Available at: http://numericalmethods.eng.usf. edu/ebooks/ runge4th 08ode ebook.htm. Accessed on 24 October 2008.

Kandhai MC, Reij MW, Grognou C, van Schothorst, M, Gorris LGM, Zwietering MH (2006) Effects of preculturing conditions on lag time and specific growth rate of Enterobacter sakazakii in reconstituted powdered infant formula. Applied and Environmental Microbiology 72:2721-2729

McClure PJ, Baranyi J, Boogard E, Kelly TM, Roberts TA (1993) A predictive model for the combined effect of $\mathrm{pH}$, sodium chloride and storage temperature on the growth of Brochothrix thermosphacta. International Journal of Food Microbiology 19: $161-78$

Muytjens HL, Roelofs WH, Jaspar GHJ (1988) Quality of powdered substitutes for breast milk with regard to members of the family Enterobacteriaceae. Journal of Clinical Microbiology 26:743-746

Muytjens HL, Zanen HC, Sonderkamp HJ, Kollée LA, Wachsmuth IK, Farmer JJ (1983) Analysis of eight cases of neonatal meningitis and sepsis due to Enterobacter sakazakii. Journal of Clinical Microbiology 18: $115-120$

Nazarowec-White M, Farber JM (1997) Incidence, survival, and growth of Enterobacter sakazakii in infant formula. Journal of Food Protection 60: 226-230

Noriega FR, Kotloff KL, Martin MA, Schwalbe RS (1990) Nosocomial bacteremia caused by Enterobacter sakazakii and Leuconostoc mesenteroides resulting from extrinsic contamination of infant formula. Pediatric Infectious Disease Journal 9: 447-449

Rosset P, Noel V, Morelli E (2007) Time-temperature profiles of infant milk formula in hospitals and analysis of Enterobacter sakazakii growth. Food Control 18: 1412-1418

Rosso L, Lobry JR, Bajard S, Flandrois JP (1995) Convenient model to describe the combined effects of temperature and $\mathrm{pH}$ on microbial growth. Applied and Environmental Microbiology 61:610-616

Schabenberger O (2005) Nonlinear regression in SAS. University of California, Los Angeles, SAS Library. Available at: http:// www.ats.ucla.edu/stat/SAS/library/SASNLin_os.htm. Accessed on 27 October 2008

Simmons BP, Gelfand MS, Haas M, Metts L, Ferguson J (1989) Enterobacter sakazakii infections in neonates associated with intrinsic contamination of a powdered infant formula. Infection Control and Hospital Epidemiology 10: 398-401

Skladal P, Mascini M, Salvadori C, Zannoni G (1993) Detection of bacterial contamination in sterile UHT milk using an L-lactate biosensor. Enzyme and Microbial Technology 15: 508-512

Tamplin ML, Paolib G, Marmera BS, Phillips J (2005) Models of the behavior of Escherichia coli O157:H7 in raw sterile ground beef stored at 5 to $46{ }^{\circ} \mathrm{C}$. International Journal of Food Microbiology 100:335-344

Telang S, Berseth CL, Ferguson PW, Kinder JM, DeRoin M, Petschow BW (2005) Fortifying fresh human milk with commercial powdered human milk fortifiers does not affect bacterial growth during 6 hours at room temperature. Journal of the American Dietetic Association 105: 1567-1572

Van Acker JV, Smet FD, Muyldermans G, Bougatef A, Naessens A, Lauwers S (2001) Outbreak of necrotizing Enterocolitis associated with Enterobacter sakazakii in powdered milk formula. Journal of Clinical Microbiology 39: 293-297

Windholz M, Budavari S, Blumetti R, Otterbein E (1983) The merck index. 10th ed. New Jersey: Merck and Co., Inc. $7458 \mathrm{p}$

Zwietering MH, Jongenburger I, Rombouts FM, vaN'T Riet K (1990) Modeling of the Bacterial Growth Curve. Applied and Environmental Microbiology 56: 1875-1881

Zwietering MH, Koos JT, Hasenack BE, Wit JC, van'T Riet K (1991) Modeling of bacterial growth as a function of temperature. Applied and Environmental Microbiology 57:1094-1101 